\title{
GET STARTED
}

\section{Turn science into art}

Here are some tips for getting the most out of the experience of creating art for science.

- Establish a working relationship with an illustrator long before you will need her or him — when you start writing a review article, for example, or when pursuing outreach projects for schools or museums. - Seek out illustrators who have expertise in areas related to your research and look through their portfolios for artistic styles that you like. Scientists typically find artists through referrals from colleagues or through online searches for illustrators in their geographic area or field of study. The Guild of Natural Science Illustrators in Washington DC maintains a list of contacts, and many illustrators share their own work on Twitter under \#sciart. - Clearly establish the data points that need to be in the art from the outset, so that the end product is accurate. But allow the artist to maximize the visual impact of their illustration.

- Be bold with ideas. One image isn't the definitive description of a scientific theory, so it's fine if an image includes some ambiguity about unknowns or hypotheses as long as it's done with sufficient context. - Seek illustrators who ask questions. You should aim to find an artist who engages with your work. J.M. cautions against enlisting professional help just to make a paper more decorative. Scientists who want to save money and create their own art and figures can use Microsoft Excel, molecular-visualization software and tools such as Adobe Photoshop and Illustrator, but those without artistic training may find they need to invest time in learning how to use the programs.

But they should consider more than just the money when making that choice. Hiring an illustrator saved Benz's two graduate-student co-authors from a huge time sink. "For them to not have to spend hours on learning how to draw a figure was hugely helpful," she says. "There was a direct impact on our work."

And although the right software can help a researcher to produce simple figures and visualize single molecules, that will not always result in a professional-style animation or illustration. Researchers who are not artists tend to lack the sense of design and aesthetics that are a keystones of fabulous artwork. "Where illustrators come in is in their knowledge of colour theory, using composition to guide someone's eye around a page or image in the right order," says O'Reilly. "Or drawing their eye to the centre of interest."

When Berry published a paper about a different fossil forest, his institution's press office asked him for images. With no illustrator accessible at the time, he sketched out trees by hand and sent his line drawings to a colleague who helped to add colour. The image is now widely used on websites, news stories and in research presentations, Berry says. Although his drawing was much simpler than Leshyk's, the process still took him nearly two weeks. "It was a lot of fun," he says. "But I'm not sure I could do it again. That was the first time I tried to draw a whole forest to a standard good enough to let other people look at." The experience underscored to him how much effort - and talent - is required for illustration. Since then, he has chosen to seek professional help when he needs artwork.

Yet the value of professional scientific illustration has been tough to quantify or explain to many. Few, if any, studies have examined its impact on a manuscript, presentation or grant proposal. But many researchers vow that illustrated manuscripts get better results. "Anecdotally, people say you get more citations, or reviewers are happier with a paper, if you have good figures," Patterson says. "Or if you have a cover image, it'll get more attention. But the actual data behind that are lacking."

Still, researchers agree that whether through a simple graphic or a $3 \mathrm{D}$ animation, the visual communication of science is growing increasingly important. Some researchers think that professionally made figures can ease a manuscript's path through peer review. Although this is tough to verify, geneticist Deborah Kurrasch of the University of Calgary in Canada says that she has opted to work with illustrators many times before submitting a paper. And when she's acting as a reviewer, she adds, well-made figures make it easier to read and understand the data.

"Making data into art takes skill," Berry says. "If I had the resources, I would always hire an illustrator."

Jyoti Madhusoodanan is a freelance writer in San Jose, California.

\section{CORRECTION}

The Careers Feature 'Doctor's advice' (Nature 533, 429-430; 2016) incorrectly described Jelena Kovačević as a biomedical engineer. She is, in fact, an electrical engineer.

\section{TRADE TALK College 'mayor'}

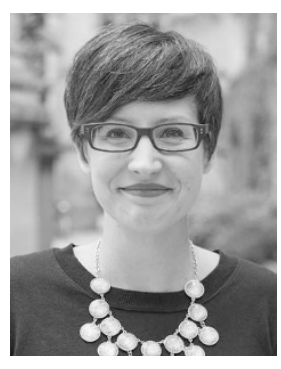

Elise Covic helps to design academic programmes at the College of the University of Chicago in Illinois. She explains what she does and how she gained the experience that would launch her career there while she was doing her PhD in computational neuroscience.

\section{What do you do as deputy dean at the college?}

When I was being recruited for this position, I was told I would be the mayor of a small, crazy town, and that I wouldn't know what problems would hit me when I woke up. I make decisions about awards for students and faculty, curricula development, development money, disciplinary actions. We have initiatives that help faculty members to help students to get the most substantive experience. I feel so lucky.

\section{When did you first consider this kind of career?}

By the second year of my $\mathrm{PhD}$ programme, I had begun to think that I didn't want a career that was research-based, but I didn't want to tell my principal investigator (PI). I was at a poster session, and my PI was proud of me, telling me I should talk to so-and-so about postdocs. Right then, I said, "We need to talk. I don't want my own lab." He said, "I don't know if I can mentor you, but let me introduce you to some friends." He directed me to the US National Science Foundation's deputy director - she invited me to call and e-mail, to come up with a plan.

\section{What happened next?}

I had an honest conversation with myself: what do I like to do? I love science. I love organizing. And I like to boss people around, so it was clear I could do administration. My PI said, "Why don't you run this undergraduate research programme with me?" He taught me how to administer grants and lab budgets, to deal with government agencies, to handle regulatory-compliance issues with the university. I had in-depth training. Other people could gain similar experience, if they ask the right question.

\section{INTERVIEW BY MONYA BAKER}

This interview has been edited for length and clarity. See go.nature.com/1svOHIM for more. 